\title{
Cytokine response and oxidative stress status in dairy cows with acute clinical mastitis
}

\begin{abstract}
In the friction process of two materials and in the presence of some proper lubricants, the wear process manifest itself as a material transfer from an element of the friction couple on the other, process specific to the selective transfer mechanism. The selective transfer can be sure achieved in a friction couple if there is a favorable energy, the relative movement and if in the friction area is a material made by copper and the lubricant is adequate (glycerin). The selective transfer mechanism is characterized by the physicochemical processes, which take place in the contact zones of the friction couples, and which to allow the selective transfer of some elements of the materials from a surface to the other, forming a thin superficial layer with the superior properties at wear and friction. This is a condition for any friction couple of high efficiently and a normal self-adjusting phenomena. The forming of this layer on the contact surfaces makes as fiction force to be reduced. It is in closely related to the structure formed by the selective transfer, between the metallic friction surfaces and with the properties these surface layers metallic.
\end{abstract}

The most important parameters concerning the physical state of the superficial layers are micro-tensions, the structure and its modification on friction surfaces, the structure defects as well as the way of distribution of the additions and of the alloying elements from alloy. The purpose of the present paper is research these parameters by the structural analysis with X-rays, as the research method of the thin superficial layers.
Volume 3 Issue I - 2016

\section{Hussam Mohamed Mohamed Ibrahim,' Youssef Yehia El-seedy, ${ }^{2}$ Naglaa Abdelmegid Gomaa $^{3}$}

'Department of Internal Medicine, Infectious and Fish Diseases, Mansoura University, Egypt

${ }^{2}$ Department of Physiology, Mansoura University, Egypt

${ }^{3}$ Department of Animal Medicine, Kafr El-sheikh University, Egypt

\section{Correspondence: Hussam Mohamed Mohamed Ibrahim} Department of Internal Medicine and Infectious Diseases, Faculty of Veterinary Medicine, Mansoura University, Mansoura 35516, Egypt, Tel 002050221 4233, 0020100529 0592, Emaildr_hussamhabosha@yahoo.com

Received: October 13,2015 | Published: January 12, 2016

Keywords: oxidative stress, pro-inflammatory cytokines, antioxidants, dairy cow, acute clinical mastitis

\section{Introduction}

Bovine mastitis is considered a major disease that causes economic losses in dairy industry ranging from decrease in milk production to reproductive and metabolic disorders in dairy cows. ${ }^{1,2}$ During mastitis, immune cells in the body recognize invading pathogens and become activated which release inflammatory mediators including nitric oxide, prostaglandins, and cytokines. These mediators promote local inflammation and increased blood flow to the infected tissue, inflammatory cytokines play a key role in stimulating systemic inflammatory responses, including increased body temperature, increased heart rate, and decreased feed intake. ${ }^{3}$ Cytokines, including tumor necrosis factor- $\alpha$ (TNF- $\alpha$ ), interleukin- $1 \beta$ (IL-1 $\beta)$, interleukin6(IL-6), and interleukin-12 (IL-12) are able to alter many physiological systems acting through many of the same signaling cascades and often produce similar responses in cells. In addition, phagocytes produce reactive oxygen species that are needed for killing bacteria during inflammatory process. ${ }^{4}$

Cytokines are crucial in driving the acute-phase response operating at every stage in the crucial early events that promote acute inflammation. Cells that make up the innate immune response, including neutrophils, natural killer cells, macrophages, mast cells, and eosinophils, all produce and respond to cytokines generated within seconds of tissue insult. Cytokines prime leukocytes for response to microbial stimuli; and amplify the release of reactive oxygen intermediates, nitric oxide, vasoactive amines, and neuropeptides, and the activation of kinins and arachidonic acid derivatives, prostaglandins, and leukotrienes, which regulate cytokine release. ${ }^{5,6}$
During lactation, mammary epithelial cells exhibit a high metabolic rate and thus produce large amounts of reactive oxygen species and lipid peroxides in vivo. ${ }^{7}$ Increased reactive oxygen species level or decreased antioxidants can disrupt the balance between oxidants and antioxidants which is referred to as oxidative stress. ${ }^{8}$ This create a more oxidizing environment that facilitate the binding of pathogens or antigens to effector cells leading to a hyper-responsive innate immune system and enhanced production of cytokines. ${ }^{9}$ Reactive oxygen species can oxidize macromolecules such as lipids, proteins and DNA and cause direct oxidative cell injury or indirectly can modify metabolic pathways. ${ }^{10}$ Similarly, the creation of a markedly reduced environment by addition of antioxidants blunts all of the above primary responses of the innate immune system.

Lipid peroxides, mediators linking plasma lipids to inflammation, are produced when intracellular lipids encounter reactive oxygen species such as hydrogen peroxide $\left(\mathrm{H}_{2} \mathrm{O}_{2}\right)$ activating inflammatory cascades, which in turn alter nutrient metabolism. Reactive oxygen species are especially harmful to immune cells and can decrease the ability of the immune system to respond to infection. ${ }^{11}$ Previous studies conducted by Weiss et al., ${ }^{12}$ revealed that the increased lipid peroxidation in clinical mastitis reduces the levels of some antioxidant molecules leading to an increase in the oxidative stress state. ${ }^{12}$

Vitamins and minerals have long been recognized as antioxidants in the animal udder health and production. However, they also have specific roles in mastitis of dairy cows, such as vitamin A, $\beta$-carotene, vitamin $\mathrm{C}$, vitamin $\mathrm{E}$, selenium, zinc and copper. ${ }^{13,14}$ In the antioxidant system, zinc is a component of copper-zinc superoxide dismutase. Zinc also induces synthesis of metallothionein, a metal binding protein 
that may scavenge hydroxide radicals. ${ }^{15}$ In addition to an antioxidant role, zinc may affect immunity via its important role in cell replication and proliferation. ${ }^{16}$ The aim of the present study is to evaluate the role of oxidative stress biomarkers, antioxidant enzymes and metabolites, and pro-inflammatory cytokines as possible biomarkers for acute clinical mastitis in dairy cow.

\section{Materials and methods}

\section{Animals}

A total of 100dairy cows at 3-10years of age were studied. Of all, 50 were exhibiting the clinical signs of acute clinical mastitis. In addition, 50 apparently healthy dairy cows within the same age and under the same environmental condition were randomly selected as a control group. The present study was carried out between January, 2014 and March, 2015 at Damietta governorate, Egypt.

\section{Clinical examination}

Data concerned with the case history, clinical findings, and medical record for each cow under investigation were recorded. A detailed clinical examination of the diseased dairy cows, including examination of the mammary gland and its secretion was carried out, and the clinical findings were recorded and scored (Table 1) according to Jánosiet al. ${ }^{17}$

Table I Clinical signs of acute clinical mastitis dairy cows

\begin{tabular}{|c|c|c|c|}
\hline & Score I & Score 2 & Score 3 \\
\hline $\begin{array}{l}\text { Systemic } \\
\text { signs }\end{array}$ & None & $\begin{array}{l}\text { Rectal temperature: } \\
\leq 40.5 \text { and/or in } \\
\text { appetence and } \\
\text { mild to moderate } \\
\text { depression. }\end{array}$ & $\begin{array}{l}\text { Rectal temperature: } \\
>40.5^{\circ} \mathrm{C} \text { and/or } \\
\text { anorexia, severe } \\
\text { depression, decreased } \\
\text { milk production and } \\
\text { recumbency. }\end{array}$ \\
\hline Local signs & None & $\begin{array}{l}\text { Hotness, moderate } \\
\text { swelling and } \\
\text { tenderness of the } \\
\text { affected quarter(s). }\end{array}$ & $\begin{array}{l}\text { Hotness, severe swelling, } \\
\text { firmness and the } \\
\text { affected quarter(s) very } \\
\text { sore to touch. }\end{array}$ \\
\hline $\begin{array}{l}\text { Milk } \\
\text { appearance }\end{array}$ & Normal & $\begin{array}{l}\text { Slightly watery, } \\
\text { discolored, and/or } \\
\text { clots and flakes. }\end{array}$ & $\begin{array}{l}\text { Consistency serum-like, } \\
\text { pus-like and/or bloody } \\
\text { stained. }\end{array}$ \\
\hline
\end{tabular}

There are three categories of acute clinical mastitis: abnormal milk, abnormal gland and an abnormal cow (systemic disease). Abnormal milk is visibly abnormal (i.e. is not 'drinkable') such as a watery appearance, flakes, clots, and/or pus. An abnormal gland characterized by sudden onset of redness, hotness, swelling, hardness, and tenderness when compared with other normal quarters. An abnormal cow is pyrexic, depressed or has decreased appetite and/or milk production, reduced rumen function, rapid pulse, dehydration, weakness, and reduced mobility, due to the pain of a swollen udder or simply due to feeling unwell.

\section{Blood samples collection}

Two venous blood samples $(10 \mathrm{~mL}$ each) were collected from each cow via jugular vein puncture. The first blood sample was collected into a clean centrifuge glass tube (Digisystem Laboratory Instrument, His Chih city, Taiwan) containing $5 \mathrm{mg}$ of sodium ethylene diaminetetraacetic acid (EMD Chemicals Inc.) as anticoagulant to separate plasma for evaluation of the activity of reduced glutathione (GSH), glutathione reductase (GR), catalase (CAT), superoxide dismutase (SOD) and level of malondialdehyde (MDA), nitric oxide (NO), IL-6 and TNF- $\alpha$. Meanwhile, the second blood sample was collected into a clean centrifuge glass tube without anticoagulant to separate serum for evaluation of iron and zinc. The separated serum and plasma were kept frozen at $-80^{\circ} \mathrm{C}$ for further biochemical analysis.

\section{Biochemical analysis}

Total antioxidant capacity (TAC) and activity of GSH, GR, CAT, SOD as well as level of MDA, NO, iron and zinc were measured spectrophotometerically (Robonik biochemistry automatic analyzer, Robonik India PVT LTD, India) following standard methods using commercially available test kits (Biodiagnostic, Cairo, Egypt). The ratio of the total peroxide levels to the TAC gave the oxidative stress index (OSI), an indicator of the degree of oxidative stress. ${ }^{18}$

The OSI value was calculated as follows:

$$
O S I=\frac{(\text { total peroxide mmol } / \mathrm{l})}{(\text { TAC } \mathrm{mmol} / \mathrm{l})} \times 100
$$

However, plasma TNF- $\alpha$ and IL-6 level was ELISA assayed (Robonik Elisa Plate Reader, Robonik India PVT LTD, India) following standard method using commercially available ELISA test kits (Boster Biological Technology, Pleasanton, Alameda County, California).

\section{Statistical analysis}

Data analysis was performed using a statistical software program (Graph pad Prism for Windows version 5.0, GraphPad Software, Inc., San diego, CA, USA). D'Agostino and Pearson omnibus normality test was used to assess normality. Data were normally distributed; therefore, mean and standard deviation were statistically analyzed and presented. Paired-sample T-test was used to assess statistical differences between the groups. Correlations between biochemical parameters were assessed by using Spearman correlation analysis. For all statistical examinations, results were considered significant at $\mathrm{p}<0.05$.

\section{Results}

Clinically, in dairy cows with acute clinical mastitis, there was a significant $(\mathrm{p}<0.05)$ increase in the clinical index score compared with control group. The recorded clinical index score expressed as $($ Mean \pm SD) for dairy cows with clinical mastitis was $2.44 \pm 0.50$. Meanwhile, the index score for control group was $1.00 \pm 0.00$.

Biochemically, in dairy cows with clinical mastitis, there were a significant $(\mathrm{p}<0.05)$ decrease in the TAC, activity of GSH and CAT as well as in the level of zinc and iron (Table 2) (Table 3). However, there was a significant $(\mathrm{p}<0.05)$ increase in the levels of MDA, NO, IL-6 and TNF- $\alpha$, activity of SOD and the OSI (Table 2) (Table 3). In dairy cows with acute clinical mastitis, there was a negative correlation between MDA and SOD ( $\mathrm{r}=-0.653)$, MDA and IL-6 $(\mathrm{r}=-0.860)$, and GR and IL-6 ( $r=-0.928)$. 
Table 2 Antioxidant enzymes activity and oxidative stress markers (Mean \pm SD) in clinically healthy cows and in those with acute clinical mastitis

\begin{tabular}{|c|c|c|c|c|c|c|c|c|}
\hline Groups & $\mathrm{TAC}(\mathrm{mmol} / \mathrm{L})$ & $\mathbf{G S H}(\mathrm{mg} / \mathrm{dL})$ & GR(U/L) & CAT(U/L) & $\operatorname{SOD}(\mathrm{U} / \mathrm{mL})$ & $\operatorname{MDA}(\mathrm{nmol} / \mathrm{mL})$ & $\mathrm{NO}(\mu \mathrm{mol} / \mathrm{L})$ & OSI \\
\hline $\begin{array}{l}\text { Control } \\
(n=50)\end{array}$ & $0.82 \pm 0.07$ & $1.80 \pm 0.07$ & $0.87 \pm 0.38$ & $454 \pm 28$ & $1658 \pm 23$ & $4.47 \pm 2.90$ & $34.70 \pm 1.92$ & $0.55 \pm 0.38$ \\
\hline $\begin{array}{l}\text { Mastitis } \\
(\mathrm{n}=50)\end{array}$ & $0.40 \pm 0.08$ & $3.09 \pm 0.25$ & $1.23 \pm 0.17$ & $156 \pm 20$ & $1815 \pm 27$ & $19.86 \pm 7.83$ & $66.06 \pm 3.02$ & $5.36 \pm 2.65$ \\
\hline$P$ value & $P=0.000$ & $P=0.000$ & $P=0.000$ & $P=0.000$ & $P=0.000$ & $\mathrm{P}=0.000$ & $P=0.000$ & $P=0.000$ \\
\hline
\end{tabular}

TAC, total antioxidant capacity; GSH, reduced glutathione; GR, glutathione reductase; CAT, catalase; SOD, superoxide dismutase; MDA, malondialdehyde; NO, nitric oxide; OSI, oxidative stress index

Table 3 Interleukin-6,TNF- $\alpha, \mathrm{Zn}$ and Fe levels (Mean \pm SD) in clinically healthy cows and in those with acute clinical mastitis

\begin{tabular}{lllll}
\hline Groups & IL-6 & TNF- $\alpha$ & Zn \\
$(n g / m L)$ & $(n g / m L)$ & $(\mu M / L)$ & $\begin{array}{l}\text { Fe } \\
(\mu M / L)\end{array}$ \\
\hline Control $(n=50)$ & $69.80 \pm 3.83$ & $7.06 \pm 0.71$ & $7.97 \pm 0.92$ & $24.46 \pm 1.39$ \\
Mastitis $(n=50)$ & $97.7 \pm 7.0$ & $12.53 \pm 1.55$ & $3.76 \pm 1.22$ & $7.18 \pm 2.43$ \\
$P$ value & $\mathrm{P}=0.147$ & $\mathrm{P}=0.000$ & $\mathrm{P}=0.000$ & $\mathrm{P}=0.000$ \\
\hline
\end{tabular}

IL-6, interleukin-6, tumor necrosis- $\alpha$, zinc and iron levels; Zn, zinc; Fe, iron

\section{Discussion}

Free radicals are natural end products of the intensive metabolism in cells of the living organism, including high-yielding dairy cows. When the homeostasis is disturbed principally by generation and accumulation of these free radicals, oxidative processes lead to oxidative stress causing mastitis in dairy cows. The inflammation of mammary glands can cause reduction of milk yield and unfavorable changes in the milk composition, e.g. reduction in fat, casein proteins and calcium content with a simultaneous increase in the concentration of whey proteins, sodium and chlorine. ${ }^{19}$ Clinically, in dairy cows with acute clinical mastitis, the clinical index score was significantly $(p<0.05)$ increased in comparison with control group. This could be attributed to inflammation of the mammary glands following their infection which represents the stage at which clinical mastitis occurs with varying degrees of clinical abnormalities of the udder and variable systemic effects with appearance of gross abnormalities of the milk. These findings were in agreement with those previously reported by Jánosi et al.17 In the current study, the antioxidant defense system is compromised in dairy cows with acute clinical mastitis, which is evidenced by decreased plasma TAC and increased MDA level, which may indirectly indicate increased whole free radical activity with a resultant increased OSI reflecting the state of oxidative stress in such cases. ${ }^{20}$

Reduced glutathione is present in living cells at high concentrations. It becomes oxidized upon reaction with reactive oxygen species to glutathione radical which can be regenerated to its reduced form by glutathione reductase..$^{21}$ In this study, the plasma GSH concentration in dairy cows with acute clinical mastitis was significantly increased $(\mathrm{p}<0.01)$ compared to control group. The increased GSH concentration could be explained by the enhancement of activities of both types of enzymes glutathione peroxidase (GPx) and GR, leading to intense regeneration of GSH from the oxidized form (GSSH) obtained after reduction of peroxides into alcohols. ${ }^{22}$ In contrast, some studies recorded a decrease in GSH in dairy cows with acute clinical mastitis. ${ }^{23}$ This variation could be attributed to different GPx activity associated with different bacterial pathogens. ${ }^{24}$

There was a significant increase in the level of GR and SOD in diseased cow compared to healthy ones which was probably a response to the higher superoxide radicals $\left(\cdot \mathrm{O}_{2}^{-}\right)$generation as a result of inflammatory reactions in the mammary gland tissue. SOD catalyzes the dismutation of $\bullet \mathrm{O}_{2}^{-}$into oxygen and $\mathrm{H}_{2} \mathrm{O}_{2}$, and it is an important antioxidant defense mechanism in aerobic organisms, although too much SOD may sometimes be deleterious. These findings were in accordance with the findings of other authors. ${ }^{25-27}$ The protective effect of CAT has been demonstrated in bovine neutrophilinduced model of mammary cell damage. ${ }^{28}$ In the present study, there was a significant decrease in CAT activity in dairy cows with acute clinical mastitis. Such decrease might be attributed to its increased consumption to counteract reactive oxygen species produced from inflamed mammary glands, suggesting a compromise in antioxidant defense of the body. ${ }^{23}$

Macrophages, neutrophils and other phagocytic cells considered as the potent cells of immune response of mammary glands against microbial infection. Those cells generated large amounts of reactive oxygen species and reactive nitrogen species that considered as the main cause of lipid peroxidation which is used as an indicator of oxidative stress in such tissues. ${ }^{29}$ Lipid peroxidation is a wellestablished mechanism of oxidative damage caused by reactive oxygen species, and measurement of the MDA provides a convenient index of lipid peroxidation. ${ }^{30}$ In this study, the mean level of MDA was significantly higher in dairy cows with acute clinical mastitis compared with control group indicating a worse state of oxidative stress as previously recorded by Ranjan et al. ${ }^{31}$ and Jhambh et al. ${ }^{23}$ Nitric oxide is one of the most important reactive nitrogen radicals; which operate in a variety of tissues such as epithelial cells and macrophage of mammary gland, producing a significant amount of $\mathrm{NO}$ that mediates inflammation during mastitis. ${ }^{32}$ In this study, there was a significant increase in plasma NO in dairy cows with acute clinical 
mastitis in comparison with control group, similar to that reported by Atakisi et al. ${ }^{33}$ In animals suffering mastitis, neutrophils produce considerable amount of $\mathrm{NO}$ and the myeloperoxidase enzyme, i.e. substances that together may lead to the formation of nitrotyrosine, which has the ability to disintegrate proteins and have a destructive effect on tissues. ${ }^{19}$

Enhancement of cytokines production is considered a non-specific defense mechanism of the body against intra-mammary infection playing not only a critical role in protection against bacterial infection, but also involved in the pathogenesis and development of symptoms in infection. ${ }^{19,34}$ Numerous factors promote cytokines expression in vivo, including cell-cell contact, immune complexes/ autoantibodies, local complement activation, microbial species and their soluble products, reactive oxygen and nitrogen intermediates, trauma, ischemia, DNA (mammalian or microbial), and cytokines themselves in autocrine loops. ${ }^{35}$ Depending on this; the IL- 6 and TNF- $\alpha$ level was significantly increased in dairy cows with acute clinical mastitis compared with healthy group. The increased IL- 6 may be because of increased MDA level as IL-6 level was positively correlated with by-products of oxidative stress as previously stated by Moldoveanu et al. . $^{19,36}$

However, increase of TNF- $\alpha$ level in the present study is due to the binding of the lipopolysaccharide (LPS) to binding protein (LBP) complex to form the cluster of differentiation 14 (CD14) molecules. ${ }^{37}$

Tumor necrosis- $\alpha$ is a potent activator of leukocytes and enhances the phagocytosis and killing of mastitis pathogens by bovine neutrophils. ${ }^{38}$ In the current study, chemotactic factors released by infectious bacteria and other components of the immune system are the signals for neutrophil recruitment to sites of infection. However, this influx of neutrophils is a double-edged sword. This may cause not only an inflammatory reaction that results in the elimination of infection, but also tissue damage that leads to fibrosis and impaired mammary function. ${ }^{19,39}$

Trace elements as copper, iron, zinc, and manganese play important roles in several biochemical processes as they are essential component in the antioxidant enzymes as SOD and catalase. ${ }^{40}$ Therefore, participation of zinc as a component of the oxidant defense mechanism was indicated and its deficiency is associated with decreased leukocyte function, increased susceptibility to bacterial infection ${ }^{41}$ with a resultant of a state of oxidative stress. ${ }^{42}$ In this study, there was a significant decrease in zinc and Iron in dairy cows with acute clinical mastitis compared with healthy cows. Decreased serum zinc and iron level are regarded as non-specific host defense mechanisms against bacterial infection, which will reduce the availability of these divalent cations needed for bacterial growth as previously stated by Ranjan et al. ${ }^{31} \&$ Failla. ${ }^{43}$ Moreover, sequestration of iron may, also be a mechanism to reduce generation of oxygen radicals, which are potent mediators of tissue damage during acute inflammation. ${ }^{44}$

\section{Conclusion}

The results of the current study showed that the oxidative stress was the principal factor causing dysfunction of the immune system of the organism impairing the response to inflammatory conditions, leading to numerous diseases in dairy cows, above all to mastitis. Under oxidative stress, which leads to a reduced resistance to the invasion of pathogenic micro-organisms, the probability of appearance of inflammatory conditions and especially of mastitis increases. All the results point to dairy cows with acute clinical mastitis as a significant factor in alterations of the oxidant and antioxidant balance in plasma associated with elevation of pro-inflammatory cytokines, resulting in potent oxidative stress, which could be a potential biomarker for diagnosing of bovine mastitis and monitoring health status of udder. Therefore, mastitis is a disease which not only reduces cows' productivity, but also leads to deterioration of the milk chemical composition and quality.

\section{Acknowledgements}

None.

\section{Conflict of interest}

Author declares that there is no conflict of interest.

\section{References}

1. Seegers H, Fourichon C, Beaudeau F. Production effects related to mastitis and mastitis economics in dairy cattle herds. Vet Res. 2003;34(5):475-479.

2. Santos JE, Cerri RL, Ballou MA, et al. Effect of timing of first clinical mastitis occurrence on lactational and reproductive performance of Holstein dairy cows. Anim Reprod Sci. 2004;80(1-2):31-45.

3. Dantzer R, Kelley KW. Twenty years of research on cytokine-induced sickness behavior. Brain Behav Immun. 2007;21(2):153-160.

4. Thannickal VJ, Fanburg BL. Reactive oxygen species in cell signaling. Am J Physiol Lung Cell Mol Physiol. 2000;279(6):L1005-L1028.

5. Baumann H, Gauldie J. The acute phase response. Immunol Today. 1994;15(2):74-80.

6. Kuby J, Kindt T, Osborn B, et al. Immunology. 5th ed. USA: WH Freeman and Company; 2003.

7. Jin L, Yan SM, Shi BL, et al. Effects of vitamin A on the milk performance, antioxidant functions and immune functions of dairy cows. Animal Feed Science and Technology. 2014;192:15-23.

8. Sordillo LM, Aitken SL. Impact of oxidative stress on the health and immune function of dairy cattle. Vet Immunol Immunopathol. 2009;128(1-3):104-109.

9. Maddox JF, Aherne KM, Reddy CC, et al. Increased neutrophil adherence and adhesion molecule mRNA expression in endothelial cells during selenium deficiency. J Leukoc Biol. 1999;65(5):658-664.

10. Miller JK, Brzezinska-Slebodzinska E, Madsen FC. Oxidative stress, antioxidants, and animal function. J Dairy Sci. 1993;76(9):2812-2823.

11. Spears JW, Weiss WP. Role of antioxidants and trace elements in health and immunity of transition dairy cows. Vet J. 2008;176(1):70-76.

12. Weiss WP, Hogan JS, Smith KL. Changes in vitamin C concentrations in plasma and milk from dairy cows after an intramammary infusion of Escherichia coli. J Dairy Sci. 2004;87(1):32-37.

13. Smith KL, Harrison JH, Hancock DD, et al. Effect of vitamin E and selenium supplementation on incidence of clinical mastitis and duration of clinical symptoms. J Dairy Sci. 1984;67(6):1293-1300.

14. Weiss WP, Hogan JS. Effects of dietary vitamin C on neutrophil function and responses to intramammary infusion of lipopolysaccharide in periparturient dairy cows. J Dairy Sci. 2007;90(2):731-739.

15. Prasad AS, Bao B, Beck Jr FW, et al. Antioxidant effect of zinc in humans. Free Radic Biol Med. 2004;37(8):1182-1190.

16. Weiss WP, Spears JW. Vitamin and trace mineral effects on immune function of ruminants. In: Sejrsen K, editors. Ruminant Physiology. Utrecht: Wageningen Academic Publishers; 2006. p. 473-496. 
17. Jánosi S, Kulcsár M, Kóródi $P$, et al. Energy imbalance related predisposition to mastitis in group-fed high-producing postpartum dairy cows. Acta Vet Hung. 2003;51(3):409-424.

18. Harma M, Harma M, Erel O. Increased oxidative stress in patients with hydatidiform mole. Swiss Med Wkly. 2003;133(41-42):563-566.

19. JóźwikA, Krzyżewski J, Strzałkowska N, et al. Relations between the oxidative status, mastitis, milk quality and disorders of reproductive functions in dairy cows - a review. Animal Science Papers and Reports. 2012;30(4):297-307.

20. Celi P. Biomarkers of oxidative stress in ruminant medicine. Imunopharmacology Immunotoxicology. 2011;33(2):233-240.

21. Kohen R, Nyska A. Oxidation of biological systems: oxidative stress phenomena, antioxidants, redox reactions and methods for their quantification. Toxicol Pathol. 2002;30(6):620-650.

22. Kizil O, Akar Y, Saat N, et al. The plasma lipid peroxidation intensity (MDA) and chain-breaking antioxidant concentrations in the cows with clinic or subclinic mastitis. Revue MédVét. 2007;158(11):529-533.

23. Jhambh R, Dimri U, Gupta VK, et al. Blood antioxidant profile and lipid peroxides in dairy cows with clinical mastitis. Vet world. 2013;6(5):271-273

24. Matei ST, Groza I, Bogdan L, et al. Correlation between mastitis pathogenic bacteria and glutathione peroxidase activity in cows milk. Bulletin of University of Agricultural Sciences AND Veterinary Medicine Cluj-Napoca. Veterinary Medicine. 2011;1(68):1-5.

25. Evelo CT, Palmen NG, Artur Y, et al. Changes in blood glutathione concentrations, and in erythrocyte glutathione reductase and glutathione S-transferase activity after running training and after participation in contests. Eur J Appl Physiol Occup Physiol. 1992;64(4):354-358.

26. Ohno Y, Aoki N, Maeda M. Effects of natural human interferon-alpha, -beta and -gamma on interleukin 2 production in human peripheral lymphocytes. Immunol Lett. 1988;17(4):339-344.

27. Halliwell B, Chirico S. Lipid peroxidation: its mechanism, measurement, and significance. Am J Clin Nutr. 1993;57(5 Suppl):715S-725S

28. Boulanger V, Zhao X, Lacasse P. Protective Effect of Melatonin and Catalase in Bovine Neutrophil-induced Model of Mammary Cell Damage. J Dairy Sci. 2002;85(3):562-569.

29. Bozukluhan K, Atakisi E, Atakisi O. Nitric oxide levels, total antioxidant and oxidant capacity in cattle with foot-and-mouth-disease. Kafkas Univ Vet Fak Derg. 2013;19(1):179-181.

30. Nielsen F, Mikkelsen BB, Nielsen JB, et al. Plasma malondialdehyde as a biomarker for oxidative stress: reference interval and effects of life style factors. Clin Chem. 1997;43(7):1209-1214.
31. Ranjan R, Swarup D, Naresh R, et al. Enhanced erythrocytic lipid peroxides and reduced plasma ascorbic acid, and alteration in blood trace elements level in dairy cows with mastitis. Vet Res Commun. 2005;29(1):27-34.

32. Bouchard L, Blais S, Desrosiers C, et al. Nitric oxide production during endotoxin-induced mastitis in the cow. Journal of Dairy Science. 1999;82(12): 2574-2581.

33. Atakisi E, Bozukluhan $\mathrm{K}$, Atakisi $\mathrm{O}$, et al. Total oxidant and antioxidant capacities and nitric oxide levels in cattle with traumatic reticuloperitonitis. Veterinary Record. 2010;167(23):908-909.

34. Francis K, Palsson BO. Effective intercellular communication distances are determined by the relative time constants for cyto/chemokine secretion and diffusion. Proc Natl Acad Sci U S A. 1997;94(23):12258-12262.

35. Feldmann M, Andreakos E, Smith C, et al. Is NF-kappa B a useful therapeutic target in rheumatoid arthritis? Ann Rheum Dis. 2002;61(Suppl 2):ii13-18.

36. Moldoveanu AI, Shephard RJ, Shek PN.Exercise elevates plasma levels but not gene expression of IL-1beta, IL-6, and TNF-alpha in blood mononuclear cells. J Appl Physiol. 2000;89(4):1499-1504.

37. Schumann RR, Leong SR, Flaggs GW, et al. Structure and function of lipopolysaccharide binding protein. Science. 1990;249(4975):1429-1431.

38. Kabbur MB, Jain NC. Signal transduction pathways involved in phagocytic and oxidative burst activities of cytokine-treated bovine neutrophils. Comp Haematol Int. 1995;5(1):38-46.

39. Capuco AV, Paape MJ, Nickerson SC. In vitro study of polymorphonuclear leukocyte damage to mammary tissues of lactating cows. Am J Vet Res. 1986;47(3):663-668

40. Yang LF, Li SX. Role of antioxidant vitamins and trace elements in mastitis in dairy cows. $J$ Adv Vet Anim Res. 2015;2(1):1-9.

41. Hayajneh FMF. Plasma ascorbic acid levels in sheep infected with hydated cyst. Merit Research Journal of Agricultural Science and Soil Sciences. 2014;2(9):111-113

42. Zago MP, Oteiza PJ. The antioxidant properties of zinc: interactions with iron and antioxidants. Free Radic Biol Med. 2001;31(2):266-274.

43. Failla ML. Trace elements and hose defense: recent advances and continuing challenges. $J$ Nutr. 2003;133(5 Suppl 1):1443S-1447S.

44. Halliwell B, Gutteridge JMC. Iron as a biological pro-oxidant. ISI Atlas of Science: Biochemistry. 1988;1:48-52. 